\title{
Modification of a spatially referenced crop model to simulate the effect of spatial pattern of subsoil salinity
}

\author{
Prakash N. Dixit ${ }^{\mathrm{a}, \mathrm{b}, *}$, Deli Chen ${ }^{\mathrm{b}}$ \\ a International Crops Research Institute for the Semi-Arid Tropics (ICRISAT), P.O. Box 39063-00623, Nairobi, Kenya \\ ${ }^{\mathrm{b}}$ Melbourne School of Land and Environment, The University of Melbourne, Vic. 3010, Australia
}

\section{A R T I C L E I N F O}

\section{Article history:}

Received 11 November 2009

Received in revised form 3 September 2010

Accepted 9 September 2010

\section{Keywords:}

Spatial simulation

Dynamic impact of salinity

Water uptake

Crop model

\begin{abstract}
A B S T R A C T
High levels of subsoil salinity limit the growth and yield of dryland cereals in the Victorian southern Mallee, Australia. Currently available crop simulation models of wheat production perform poorly in this region, presumably due to their inability to account for subsoil limitations, mainly salinity. The objective of this work was to modify a spatially referenced Water and Nitrogen Management Model (WNMM) to account for the spatial pattern of subsoil salinity, by adjusting crop water uptake, in order to explain the spatial variation in wheat yield in this area. Measurements of above-ground biomass and yield of wheat, and the profile of soil salinity $(0-80 \mathrm{~cm})$ were made at 40 locations across an 88 ha paddock $\left(35.78^{\circ} \mathrm{S}\right.$, $142.98^{\circ} \mathrm{E}$ ) in the Victorian southern Mallee. The S-shaped water stress response function for crop water uptake proposed by van Genuchten (1987) was explored to modify the WNMM by adjusting the water uptake due to salinity, which significantly improved yield simulation over the original WNMM. The improvement in the model's ability to simulate wheat yield indicates that the subsoil salinity limits crop performance in the area. The incorporation of a salinity function in spatial crop models offers potential for simulating yield across a landscape and thus practicing precision agriculture provided salinity impact is considered dynamically.
\end{abstract}

(c) 2010 Elsevier B.V. All rights reserved.

\section{Introduction}

Salinity is one of the most important environmental stresses influencing the productivity of agricultural systems around the world (McWilliam, 1986). It negatively affects crop growth and yield through the development of negative osmotic potential in the root zone (Tedeschi and Menenti, 2002) as well as causing ion toxicity (Bresler et al., 1982). The presence of salts in aqueous solutions decreases osmotic potential and hinders the extraction and uptake of water by plant roots. Consequently plants are unable to meet their evapotranspiration demand despite sufficient soil water levels (Maas and Hoffman, 1977; Maas, 1986; Somani, 1991; Katerji et al., 1997; Lamsal et al., 1999). Apart from variation in extreme temperatures (Dixit and Chen, 2010a), spatially variable wheat yield in the Victorian southern Mallee, Australia could be related to subsoil constraints, notably soil salinity (Anon, 2004). A field survey (Nuttall et al., 2001a,b) and an investigation of cropping systems on Calcarosols in the Victorian southern Mallee (Nuttall et al., 2003b) showed that these soils contain variable but usually high

\footnotetext{
* Corresponding author at: International Crops Research Institute for the SemiArid Tropics (ICRISAT), P.O. Box 39063-00623, Nairobi, Kenya. Tel.: +254 20722 4565; fax: +25420722 4001.

E-mail address: p.dixit@cgiar.org (P.N. Dixit).
}

levels of salt. Salinity in many soils in this region is also reported by Incerti and O'Leary (1990) and Holloway and Alston (1992). Studies conducted by Sadras et al. (2002), Nuttall et al. (2003a) and McDonald (2006) on similar soils and climate to that used in this study have established that a significant proportion of spatial variability in grain yield of dryland crops could be attributed to the subsoil constraints mainly salinity and its effect on water uptake by the crop.

Salinity problem becomes more severe in arid and semi arid regions compared to humid and sub-humid regions, where rainfall is sufficient to leach out accumulated salts (Lamsal et al., 1999). The southern Mallee region of Victoria receives average seasonal rainfall of less than $250 \mathrm{~mm}$ (Sadras et al., 2003). The seasonal rainfall at the site used in this study ranged from $220 \mathrm{~mm}$ in 2005 to only $89 \mathrm{~mm}$ in 2006 and the long-term average for the Birchip Bureau of Meteorology site (1891-2006) about $20 \mathrm{~km}$ from the study site is $239 \mathrm{~mm}$ (Armstrong et al., 2009). Due to the low growing season rainfall and high evaporation demand, the salinity problem is severe in this region. Incerti and O'Leary (1990) reported that in 2 years the growing season rainfall was 278 and $201 \mathrm{~mm}$ and the evaporation demand $\left(E_{\text {pan }}\right)$ was 683 and $716 \mathrm{~mm}$, respectively. Average actual evapotranspiration (water use) for a wheat crop across 14 locations in Victorian southern Mallee ranged from 150 to $350 \mathrm{~mm}$ (Nuttall et al., 2003a) and from 197 to $304 \mathrm{~mm}$ near the study paddock (Dixit and Chen, 2010b). There is no irrigation used 
in the area and capillary rise is not an issue due to significant depth of the water table (30-50 m) (O'Connell et al., 1995).

In dryland regions with annual rainfall between 250 and $600 \mathrm{~mm}$, saline subsoils having electrical conductivity of saturation extract $\left(E C_{\mathrm{e}}\right)$ values between 2 and $16 \mathrm{dS} / \mathrm{m}$ can dramatically affect crop production through osmotic effects during dry periods (Rengasamy, 2002). This osmotic effect contributes to a reduced growth rate, changes in leaf colour and developmental characteristics, such as reduced root, shoot and leaf growth and hastens maturity (Steppuhn et al., 2005). Sadras et al. (2002) reported that high soil salinity in the deeper subsoil restricts wheat crop growth by reducing the osmotic potential and adsorption of water, reducing grain yield in the Victorian Mallee. The adverse effect of salinity on crop growth and yield has also been reported by several researchers (Ayers and Wescot, 1976; Maas and Hoffman, 1977; Munns and Rawson, 1999; Sadras et al., 2002; Poustini and Siosemardeh, 2004; Saqib et al., 2004).

The simplistic models based on generally accepted understanding of mechanism often explain too little of the total yield variation to be useful (Cook and Bramley, 2001). This warrants a need to improve the realism of models by adding more and more components to reflect the complexity of biological systems (Booltink et al., 2001). Despite the apparent significance of subsoil properties to crop production in Victorian southern Mallee, few quantitative data are available to define the relationships (Nuttall et al., 2003a). The low seasonal rainfall and the presence of salinity at root zone in the dryland cropping belt of Victorian southern Mallee, demand careful management of scarce water resource and improved simulation models to explain grain yield variation.

The use of simulation modelling to improve crop management decisions, optimise cropping systems and quantify environmental risks has proven to be important and valuable (Meinke and Hochman, 2000). However, subsoil limitations such as salinity or sodicity have so far limited the application of simulation models in the main cereal-growing areas of southern Mallee/North Western Victoria (Rodriguez and Nuttall, 2003).

Most of the commonly available functional models do not simulate the effects of salinity on plant growth (Adiku et al., 2001). However, there have been efforts to account for salinity. Cardon and Letey (1992) found that the S-shaped stress function proposed by van Genuchten (1987) which relates water uptake to the average salt concentration in the root zone with the use of a soil salinity stress function agreed with the measured data. Karlberg et al. (2006) also found similar results in their study when they used a physically based transient ecosystems model which uses the van Genuchten's soil salinity reduction function to determine the effect of increased soil salinity on the plant.

Attempts have been made to modify the single point models to take salinity into account (Lamsal et al., 1999; Homaee et al., 2002; Karlberg et al., 2006) in a very general sense. However, no attempts have been made to take the salinity into account, in the low rainfall areas of the wheat belt of Australia with subsoil constraints, to explain variation in the grain yield which could result from the low water extraction by the plants because of subsoil salinity. Additionally, no literature is available on the modification of the model by trying to take salinity effect dynamically i.e., by modifying the concentration of salinity in soil solution at a daily time step. Hence this work presents a novel approach and could be a valuable contribution in the way researchers have been trying to modify the crop models to account for the effect of salinity (or any other soil constraint) on grain yield especially in arid and semi arid areas.

The objective of this work is to modify a spatially referenced Water and Nitrogen Management Model (WNMM) (Li et al., 2007) to account for the effect of salinity on water uptake by the crop which can spatially simulate the effect of subsoil salinity on wheat yield.

\section{Materials and methods}

\subsection{Field experiment}

The study was conducted in an 88 ha paddock $\left(35.78^{\circ} \mathrm{S}\right.$, $\left.142.98^{\circ} \mathrm{E}\right), 20 \mathrm{~km}$ north of Birchip in the southern Mallee of Victoria, Australia in the year 2004. During the crop growing period, the average maximum and minimum temperatures were $18.4{ }^{\circ} \mathrm{C}$ and $5.2^{\circ} \mathrm{C}$, the average daily solar radiation was $14.2 \mathrm{MJ} / \mathrm{m}^{2}$ and the total rainfall at the paddock was $206 \mathrm{~mm}$.

The historical grain yields (from harvester) and biomass (from satellite imagery based on the normalized difference vegetation index, NDVI) during 1996-2002 were collected to define zones of yield variability and thus the yield-based management zones within the paddock were established (Abuzar et al., 2004; Fisher et al., 2009). The paddock area was then assigned into three yield classes (low, medium, and high) and each classified into two seasonal variability zones (variable and stable).

A large agronomic experiment was planned for a precision agriculture project and the required crop data for this study was collected from that experiment, along with the soil salinity data. The agronomic design of the experiment was tailored to meet several other objectives of the project (see Armstrong et al., 2009; Fisher et al., 2009; Rab et al., 2009; Robinson et al., 2009). The summary of the experiment is given below while the detailed layout of the experiment can be found in Rab et al. (2006).

Three experimental blocks were formed within the paddock. The first block was approximately $117 \mathrm{~m}$ wide and $700 \mathrm{~m}$ long, the second block was $117 \mathrm{~m}$ wide and $665 \mathrm{~m}$ long and the third block was approximately $117 \mathrm{~m}$ wide and $430 \mathrm{~m}$ long. Ten zones of different yield potential (two replications of stable high and low yield and three replications of variable high and low yield) were marked among those three blocks based on defined yield zones (as explained above). Each block was longitudinally divided into two sections of sowing rates ( $30 \mathrm{~kg} / \mathrm{ha}$ and $80 \mathrm{~kg} / \mathrm{ha}$ ) and each section was further divided into four longitudinal strips where different fertiliser treatments were applied. A wheat crop (variety, Yitpi) was sown at a depth of $5 \mathrm{~cm}$, and with a row spacing of $18 \mathrm{~cm}$. After tillering, nitrogen fertiliser was applied by top dressing in the form of urea that contained approximately $46 \%$ nitrogen $(\mathrm{N})$. The four different rates of fertiliser used were $0,30,56$ and $109 \mathrm{~kg} /$ ha (see Rab et al., 2006).

\subsection{Data collection}

Because of low rainfall, the effect of different nitrogen rates was not detected in the field so only the lowest and highest nitrogen treatments i.e., 0 and $109 \mathrm{~kg} / \mathrm{ha}$ were selected for analysis and plant samples were taken from 10 zones $\times 2$ sowing rates $\times 2 \mathrm{~N}$ treatments, making a total of 40 sample plots. At anthesis, above-ground plant samples were manually collected from 1 -m linear distance $(2 \times 50 \mathrm{~cm})$ from each plot and were oven dried at $70^{\circ} \mathrm{C}$ for 3 days to obtain dry weight of the above-ground biomass.

Soil cores from the middle of these 40 sample plots (four from each of 10 zones) were taken up to a depth of $80 \mathrm{~cm}$ to represent the inherent variability in each yield zone. These cores were subsequently segmented into four sections corresponding to the following depths, $0-10,10-20,20-40$ and $40-80 \mathrm{~cm}$ for the measurement of soil salinity and for particle size analysis to determine clay, sand and silt composition of the soil. These soil data were used to obtain several soil parameters used as input into the model e.g., field capacity, permanent wilting point (lower limit), saturation point and air dry moisture content.

The number and the locations of these representative soil sampling sites were chosen on the basis of variability in grain yield and apparent electrical conductivity $\left(E C_{\mathrm{a}}\right)$ obtained from an elec- 
tromagnetic induction (EM38) survey as reported by Rampant and Abuzar (2004). The soil salinity is correlated with the apparent soil electrical conductivity and is highly related to crop productivity (Freeland, 1989; Rhoades et al., 1989, 1999; Sudduth et al., 1999; Heap, 2002; Whelan and McBratney, 2003). Thereby, the varying salinity levels are inherently represented by different yield zones. In a research to observe interactions between soil properties and water use to explain yield variability, across 3 years of data collection, Armstrong et al. (2009) took 37 monitoring points in 1 year and 40 points in the other 2 years representing the three yield (low, moderate, and high) and two stability (stable and variable) zones in the same research paddock where the study for this paper was conducted.

Further, to establish the adequacy of the measured data in terms of their statistical representation of the spatial variability of subsoil salinity from the 40 representative sample points, a one-way analysis of variance (ANOVA) was carried out. The ANOVA (Genstat v.11) was performed to test whether the levels of salinity differed across the different zones of yield potential for all the soil layers. The salinity values at four different points within a zone, for a particular layer were considered blocks in the ANOVA. The results showed that the soil salinity was significantly different across the yield zones ( $p<0.001$ for all layers) which establishes that the collected soil data adequately represent the spatial heterogeneity. The maximum, minimum and mean values of $E C$ for each layer across all the yield zones are given in Table 1 .

All the soil samples were dried at $40^{\circ} \mathrm{C}$ for 3 days and then ground and sieved to pass through a $2 \mathrm{~mm}$ sieve. Altogether, there were 160 samples from 40 sample points and at four different depths. Soil salinity in terms of soil electrical conductivity $(E C, \mathrm{dS} / \mathrm{m}$, in 1:5 soil:water solution) was measured according to the standard method described by Rayment and Higginson (1992). The particle size analysis (PSA) of soil samples was carried out by the Nutrient Advantage Lab of Incitec Pivot Limited, Werribee, Victoria as described by Day (1965).

Plant samples were hand harvested from each of the 40 plots at maturity. Above-ground samples were collected from four quadrats within each plot. From each quadrat, two adjacent rows, each 1$\mathrm{m}$ long, were selected and then the bulk samples from all four quadrats, eight rows, were placed into one bag. These samples were oven dried at $70^{\circ} \mathrm{C}$ for 3 days and weighed to calculate the aboveground biomass. If the biomass of the harvested sample was less than that of at anthesis, due to decay of leaves, the biomass at anthesis was considered for the analysis. Samples were manually threshed with $100 \%$ recovery of grains to obtain grain yield. Harvest index was calculated by dividing the dry grain yield by total above-ground biomass for each harvest sample.

\subsection{Simulation with the original WNMM}

To evaluate the performance of the original WNMM (Li et al., 2007), grain yield and biomass simulations were done using input data from all the 40 points. The observed yield and biomass for different sowing rates were found similar and hence their effect was ignored for all the simulation analyses. Several important crop input parameters e.g., energy efficiency to convert radiation energy into biomass, maximum leaf area index and harvest index were adjusted to calibrate the model.

\subsection{Modification of the WNMM}

The water uptake/transpiration approach is the most commonly used method for estimating salinity stress. This approach assumes that reduced crop growth is caused by a reduced transpiration as a result of increased soil salinity (Karlberg et al., 2006).
Table 1

Salinity $(E C, \mathrm{dS} / \mathrm{m})$ values for the different soil layers in each zone.

\begin{tabular}{|c|c|c|c|c|}
\hline \multirow[t]{2}{*}{ Zone } & \multicolumn{4}{|l|}{$E C(\mathrm{dS} / \mathrm{m})$} \\
\hline & Layer $(\mathrm{cm})$ & Maximum & Minimum & Mean \\
\hline \multirow[t]{4}{*}{1} & $0-10$ & 0.075 & 0.043 & $0.058^{a}$ \\
\hline & $10-20$ & 0.119 & 0.069 & $0.091^{\mathrm{b}}$ \\
\hline & $20-40$ & 0.294 & 0.145 & $0.198^{c}$ \\
\hline & $40-80$ & 0.492 & 0.215 & $0.355^{\mathrm{d}}$ \\
\hline \multirow[t]{4}{*}{2} & $0-10$ & 0.166 & 0.080 & $0.121^{\mathrm{a}}$ \\
\hline & $10-20$ & 0.168 & 0.108 & $0.147^{b}$ \\
\hline & $20-40$ & 0.210 & 0.124 & $0.179^{c}$ \\
\hline & $40-80$ & 0.492 & 0.206 & $0.373^{d}$ \\
\hline \multirow[t]{4}{*}{3} & $0-10$ & 0.146 & 0.107 & $0.126^{\mathrm{a}}$ \\
\hline & $10-20$ & 0.217 & 0.182 & $0.202^{\mathrm{b}}$ \\
\hline & $20-40$ & 0.460 & 0.295 & $0.380^{c}$ \\
\hline & $40-80$ & 0.878 & 0.510 & $0.700^{d}$ \\
\hline \multirow[t]{4}{*}{4} & $0-10$ & 0.167 & 0.102 & $0.130^{\mathrm{a}}$ \\
\hline & $10-20$ & 0.298 & 0.167 & $0.238^{\mathrm{b}}$ \\
\hline & $20-40$ & 0.562 & 0.258 & $0.421^{c}$ \\
\hline & $40-80$ & 0.880 & 0.492 & $0.742^{\mathrm{d}}$ \\
\hline \multirow[t]{4}{*}{5} & $0-10$ & 0.103 & 0.046 & $0.078^{a}$ \\
\hline & $10-20$ & 0.246 & 0.041 & $0.162^{\mathrm{b}}$ \\
\hline & $20-40$ & 0.390 & 0.181 & $0.277^{c}$ \\
\hline & $40-80$ & 0.629 & 0.388 & $0.492^{d}$ \\
\hline \multirow[t]{4}{*}{6} & $0-10$ & 0.189 & 0.061 & $0.127^{\mathrm{a}}$ \\
\hline & $10-20$ & 0.182 & 0.120 & $0.147^{b}$ \\
\hline & $20-40$ & 0.261 & 0.116 & $0.187^{c}$ \\
\hline & $40-80$ & 0.543 & 0.242 & $0.404^{\mathrm{d}}$ \\
\hline \multirow[t]{4}{*}{7} & $0-10$ & 0.120 & 0.070 & $0.089^{a}$ \\
\hline & $10-20$ & 0.246 & 0.112 & $0.162^{\mathrm{b}}$ \\
\hline & $20-40$ & 0.440 & 0.203 & $0.325^{c}$ \\
\hline & $40-80$ & 0.724 & 0.500 & $0.620^{d}$ \\
\hline \multirow[t]{4}{*}{8} & $0-10$ & 0.227 & 0.123 & $0.196^{\mathrm{a}}$ \\
\hline & $10-20$ & 0.352 & 0.226 & $0.288^{\mathrm{b}}$ \\
\hline & $20-40$ & 0.675 & 0.442 & $0.569^{c}$ \\
\hline & $40-80$ & 1.062 & 0.768 & $0.890^{\mathrm{d}}$ \\
\hline \multirow[t]{4}{*}{9} & $0-10$ & 0.166 & 0.070 & $0.125^{\mathrm{a}}$ \\
\hline & $10-20$ & 0.196 & 0.121 & $0.156^{\mathrm{b}}$ \\
\hline & $20-40$ & 0.331 & 0.161 & $0.254^{c}$ \\
\hline & $40-80$ & 0.645 & 0.468 & $0.561^{d}$ \\
\hline \multirow[t]{4}{*}{10} & $0-10$ & 0.275 & 0.193 & $0.242^{\mathrm{a}}$ \\
\hline & $10-20$ & 0.401 & 0.384 & $0.391^{b}$ \\
\hline & $20-40$ & 0.794 & 0.559 & $0.720^{c}$ \\
\hline & $40-80$ & 1.212 & 0.783 & $0.985^{\mathrm{d}}$ \\
\hline
\end{tabular}

a, b, c and d indicate that the $E C$ values are significantly different $(p<0.001)$ across 10 zones for $0-10,10-20,20-40$ and $40-80 \mathrm{~cm}$ layers, respectively.

van Genuchten (1987) proposed the following S-shaped water stress response function:

$\alpha(h)=\frac{1}{1+\left(h / h_{50}\right)^{p}}$

where the water stress response function $\alpha(h)$ is a dimensionless function of the soil water pressure head $(0 \leq \alpha \leq 1), h$ is pressure head $(\mathrm{cm}), h_{50}$ represents the pressure head $(\mathrm{cm})$ at which the water extraction is reduced by $50 \%$, and $p$ is a dimensionless experimental constant.

This approach was explored to take the effect of salinity on water uptake similar to the studies by Steppuhn et al. (2005) and Kiani et al. (2008). The modification was made by using the following salinity stress response function for transpiration:

$T_{\mathrm{m}}=T_{\mathrm{o}} \times\left(\frac{1}{1+\left(E C / E C_{50}\right)^{p}}\right)$

where $T_{\mathrm{m}}$ is the modified transpiration ( $\mathrm{mm}$ ) due to salinity, $T_{\mathrm{o}}$ is the original transpiration $(\mathrm{mm})$ calculated by the model in absence of salinity, $E C$ is the soil salinity $(\mathrm{dS} / \mathrm{m})$ and $E C_{50}$ is the amount of 
salinity which causes transpiration to be reduced by $50 \%$. Steppuhn et al. (2005) reported that the measure used for average root-zone salinity in Eq. (2) is mainly electrical conductivity value (EC). A value of $p=3$ used by van Genuchten and Hoffman (1984), van Genuchten (1987) and van Genuchten and Gupta (1993) was taken in this analysis.

According to the above approach, the transpiration is more affected exceeding a certain threshold limit of salinity $\left(E C_{50}\right)$ and less affected below that threshold limit. Maas and Hoffman (1977) reported that empirical relationships between salinity and plant growth could be characterized by a threshold salinity value beyond which yields declines. The modification was done by incorporating Eq. (2) in the transpiration module of the model. First the model calculates transpiration based on Eq. (1) depending on the dryness and then it is modified by Eq. (2) to take salinity into account.

Within this approach, two methods were explored. In the first method EC was taken as a constant value for a particular layer assuming salinity impact to be constant. Whereas, in the second method $E C$ was made dynamic by varying it according to the water content of a particular soil layer i.e., the concentration of salt in the soil water at a daily time step assuming salinity impact to be dynamic.

To account for the salinity impact, the water balance module of WNMM was modified for each soil layer as follows:

Update available soil water (salinity)

$S W_{\mathrm{a}}=S W_{\mathrm{p}}-T_{\mathrm{m}}$

If salinity impact $=$ constant, then

$E C=$ SoilEC

$E C_{50}=\gamma$

If salinity impact = dynamic, then

$E C=\frac{\text { SoilEC } \times S W_{\mathrm{p}}}{S W_{\mathrm{a}}}$

$E C_{50}=\delta$

where $S W_{\mathrm{a}}$ is the available soil water in a soil layer in $\mathrm{mm}, S W_{\mathrm{p}}$ is the previous day soil water in that soil layer in $\mathrm{mm}, E C$ is the salinity in $\mathrm{dS} / \mathrm{m}$, SoilEC is the $E C$ value for the soil layer in $\mathrm{dS} / \mathrm{m}, E C_{50}$ is the amount of salinity which causes transpiration to be reduced by $50 \%, \gamma$ and $\delta$ are the $E C_{50}$ values for constant and dynamic method of modification, respectively. While activating the model, any of the model modification methods can be selected.

First the modified transpiration was calculated from Eq. (2). Thereafter, soil water for a particular day was modified by subtracting the modified transpiration from the soil water at previous day. The $E C$ values were the input given in to the model and were calculated for constant impact and dynamic impact of salinity by Eqs. (4) and (6), respectively.

\subsection{Comparison methods of modifications}

The two frequently used statistical indicators in the comparison and evaluation of simulation models are the root mean square error (RMSE) and the mean bias error (MBE) (Wilmott et al., 1985; Jacovides and Kontoyiannis, 1995). However, in this study, the coefficient of determination $\left(R^{2}\right)$, Normalized root mean square error (NRMSE) and modelling efficiency (EF) values (Loague and Green, 1991) were also used to investigate the quality of simulation results compared to the measured, along with the mean bias error and root mean square error

$\mathrm{MBE}=\frac{\sum_{i=1}^{n}(\mathrm{Si}-\mathrm{Oi})}{n}$
$\operatorname{RMSE}=\left(\frac{\sum_{i=1}^{n}(S i-O i)^{2}}{n}\right)^{1 / 2}$

$\mathrm{NRMSE}=\left(\frac{\sum_{i=1}^{n}(\mathrm{Si}-\mathrm{Oi})^{2}}{n}\right)^{1 / 2} \times\left(\frac{100 \%}{\bar{O}}\right)$

$\mathrm{EF}=\frac{\sum_{i=1}^{n}(\mathrm{O} i-\overline{\mathrm{O}})^{2}-\sum_{i=1}^{n}(\mathrm{Si}-\mathrm{O} i)^{2}}{\sum_{i=1}^{n}(\mathrm{O} i-\overline{\mathrm{O}})^{2}}$

where $O$ and $S$ represent observed and simulated values, respectively, the corresponding over lined characters represent mean observed and simulated values and $n$ is the number of observations. The MBE test provides information on the long-term performance of a correlation. A low MBE is desired and indicates better performance of the model. A positive value stands for the average amount of over estimation in the simulated value and vice versa (Bashahu, 2003). The RMSE value determines to what extent the simulations over or under-estimate actual measurements. It is a measure of the scatter of the data points around the 1:1 line. Low RMSE indicates little scatter, while high RMSE indicates large scatter (Zhuang et al., 2001). Generally, quantitative models are considered as accurate when they have a low bias error and low RMSE (Roggo et al., 2003). RMSE is an estimate of the inherent error in the simulation; and the normalized RMSE is a measure of error in relation to the mean. The EF value compares the simulated values to the average value of the measurements. A negative EF value indicates that the average value of the measurements gives a better estimate than the simulated values (Xevi et al., 1996). A high value of $R^{2}$ and EF indicate better performance, whereas a low value of MBE, RMSE and NRMSE indicate better performance.

\section{Results and discussion}

Average EC in the top layer $(0-10 \mathrm{~cm})$ across 10 zones was $0.13 \mathrm{dS} / \mathrm{m}$ (range $0.04-0.28 \mathrm{dS} / \mathrm{m}$ ) and in the $10-20 \mathrm{~cm}$ layer $0.2 \mathrm{dS} / \mathrm{m}$ (range $0.04-0.41 \mathrm{dS} / \mathrm{m}$ ). Soil salinity and variation in soil salinity was more evident in deeper layers. The $20-40 \mathrm{~cm}$ layer had an average $E C$ of $0.35 \mathrm{dS} / \mathrm{m}$ (range $0.12-0.8 \mathrm{dS} / \mathrm{m}$ ) and the bottom layer of $40-80 \mathrm{~cm}$ had the highest average $E C$ value of $0.6 \mathrm{dS} / \mathrm{m}$ (range $0.21-1.2 \mathrm{dS} / \mathrm{m}$ ).

Average clay and sand in the $0-10 \mathrm{~cm}$ layer was $12.9 \%$ and $77 \%$, in the $10-20 \mathrm{~cm}$ layer $20.4 \%$ and $68.4 \%$, in the $20-40 \mathrm{~cm}$ layer $30.1 \%$ and $58.6 \%$ and in the $40-80 \mathrm{~cm}$ layer $32.6 \%$ and $58.9 \%$, respectively, indicating that while top soil was sandy, subsoil had more clay. Soil salinity increased with increasing clay content which was higher for deeper layers. The association of soil salinity along with other subsoil constraints with clay content is also reported by Armstrong et al. (2009). All the soil water retention parameters except the soil water at saturation i.e., air dry moisture content, field capacity and lower limit increased with increasing levels of salinity. However, the saturation value decreased with increase in salinity.

\subsection{Simulation with the original WNMM}

When the simulated yield and biomass were plotted against their measured values, the original WNMM, without any modification to account for subsoil salinity, produced a high intercept for both yield (Fig. 1a) and biomass (Fig. 1b) and hence was biased. During the calibration process, only the value of intercept kept changing and no significant change in the value of slope was observed, this indicates that the calibration by adjusting crop input parameters alone was not improving the grain yield and biomass simulation. The original model explained about $44 \%$ and $48 \%$ of the variability $(n=40, p<0.001)$ in grain yield and biomass, respectively, with high biasness. Hence, the coefficient of determination 

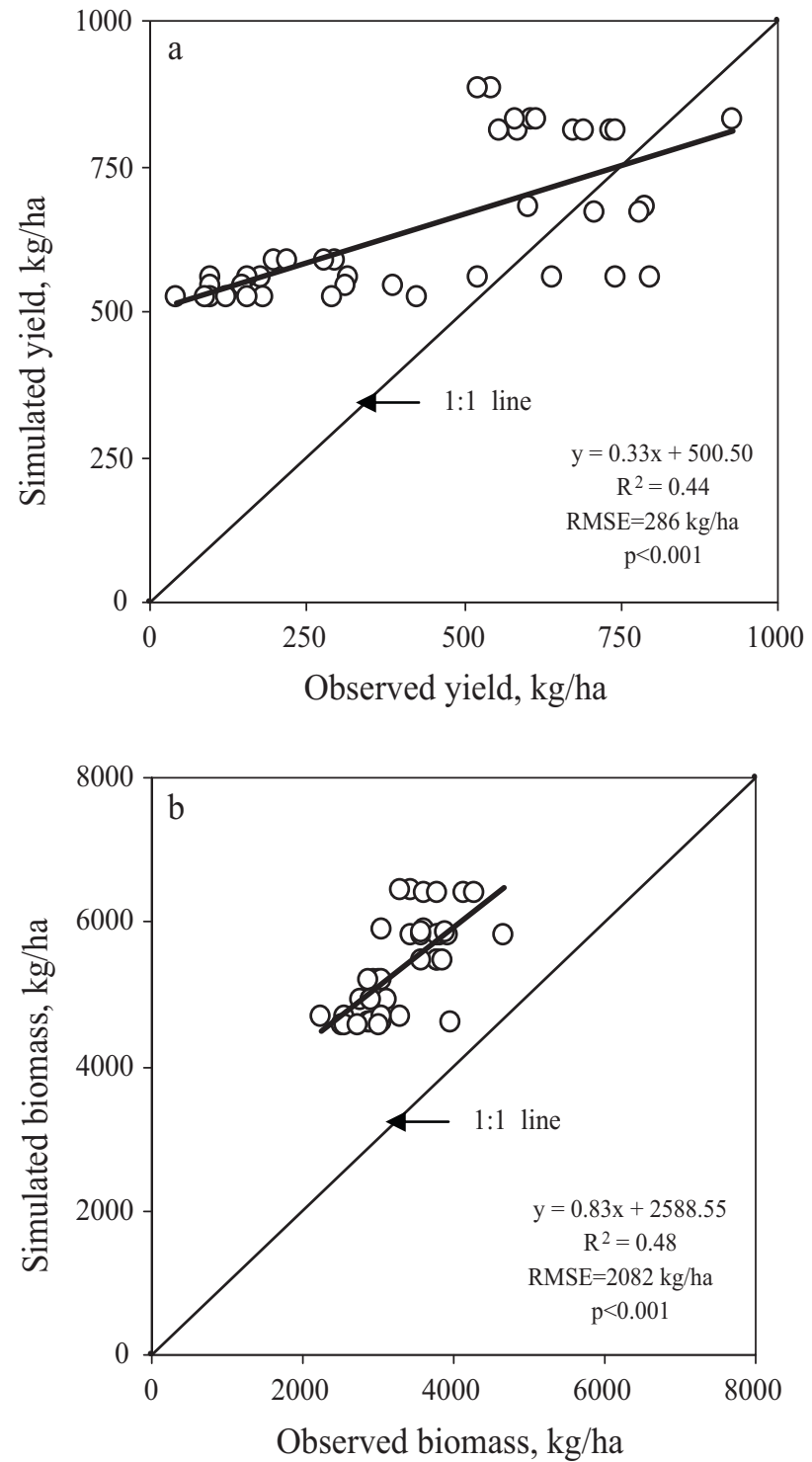

Fig. 1. Relationship between observed and simulated grain yield (a) and biomass (b) by original model.

alone, in this case, cannot be taken as the only measure to explain the performance of the model as it was biased and produced large root mean square error (RMSE) values. Large RMSE indicates poor and unsatisfactory performance of the original WNMM in the study area.

A linear regression without an intercept was conducted, to see if the regression deviates from the ideally expected $1: 1$ - line, and it produced a negative $R^{2}$ in the case of grain yield and 0.07 in the case of biomass with a slope value of more than unity indicating overestimation of yield and biomass. With traditional linear regression formulae, negative $R^{2}$, with no intercept, indicate total inadequacy of the model as reported by Christiansen and Reister (1988).

\subsection{Simulation with the modified WNMM}

\subsubsection{Constant impact of salinity}

The data from all the 40 sampling points were used to calibrate and assess the performance of the modified WNMM by taking the constant impact of salinity on water uptake by the crop. A $\gamma$ value of $0.09 \mathrm{dS} / \mathrm{m}$ was found to be most appropriate during calibration along with the crop parameters which were
Table 2a

Comparison of the different statistical parameters during simulation with original and modified model for grain yield $(n=40)$.

\begin{tabular}{lrllll}
\hline Method & \multicolumn{1}{c}{$R^{2 \mathrm{a}}$} & MBE $(\mathrm{kg} / \mathrm{ha})$ & RMSE $(\mathrm{kg} / \mathrm{ha})$ & NRMSE $(\%)$ & \multicolumn{1}{l}{ EF } \\
\hline Original & -3.46 & 252 & 286 & 65.4 & -0.3 \\
Constant impact & 0.06 & 282 & 351 & 80.3 & -0.9 \\
Dynamic impact & 0.46 & 151 & 188 & 43.1 & 0.5 \\
\hline a $R^{2}$ is for the regres
\end{tabular}

a $R^{2}$ is for the regression with no intercept.

used to calibrate the original WNMM. When the observed and simulated yield and biomass were plotted, the modified model produced a high intercept $(93 \mathrm{~kg} / \mathrm{ha}$ ) for yield showing bias with a low value of slope (0.26). This indicates that the model generally underestimated yield and was less sensitive to variation in simulated yield compared to the measured yield. However, in the case of biomass, the model produced a high negative intercept $(-1636 \mathrm{~kg} / \mathrm{ha})$ and a slope close to unity (1.04) (figures not presented). This indicates that the model was sensitive to simulation of the variation in biomass with respect to the variation in observed biomass but due to a high negative intercept, it under estimated biomass. Overall the modified model explained about $11 \%$ variability in grain yield (RMSE $=351 \mathrm{~kg} / \mathrm{ha})$ and $17 \%$ variability in biomass $(\mathrm{RMSE}=1936 \mathrm{~kg} / \mathrm{ha})(n=40, p<0.001$ for both cases $)$. The RMSE value for yield was higher than that of the original model and was similar to the original model for biomass indicating no improvement in the modified model's capabilities to simulate yield and biomass.

\subsubsection{Dynamic impact of salinity}

Out of 40 sampled data points, data from 20 randomly chosen points were used for calibrating the model after improving it by taking the dynamic impact of salinity. Data from remaining 20 points were used for validating the modified model. Crop parameters used for calibrating the original WNMM, were also used to calibrate the modified model and were found best fitted. A $\delta$ value of $0.11 \mathrm{dS} / \mathrm{m}$ was found to be the most appropriate in this case during calibration. The calibration was primarily focused on grain yield and biomass predictions.

When the simulated yield and biomass were plotted against their measured values, the modified model (dynamic impact of salinity) explained $73 \%$ of the variability in yield (Fig. 2a) and 60\% variability in biomass (Fig. 2b) with reduced RMSE in both the cases $(n=20, p<0.001)$. The reduced RMSE and the improvement in $R^{2}$ without intercept for yield (0.54) and biomass (0.49) simulations, compared to the previous method of modification and the original WNMM showed that this method improved simulation significantly. This also indicates that the modified model is good in terms of prediction of change in simulated value with respect to change in observed value $(1: 1)$ for both yield and biomass.

During validation, the modified model (dynamic impact of salinity) explained $43 \%$ of the variability in yield (Fig. 3a) and $35 \%$ variability in biomass (Fig. $3 \mathrm{~b})(n=20, p<0.01)$. The $R^{2}$ without intercept for yield (0.38) and biomass $(0.30)$ simulations also show the superiority of this method of modification over the previous one. This also indicates that model is good in predicting change in simulated value with respect to change in observed value for both yield and biomass.

When all the 40 points were considered together by the modified model (dynamic impact of salinity), the RMSE was significantly reduced for both yield (Table $2 a$ ) and for biomass (Table $2 b$ ), compared to the one obtained from modification by taking constant impact of salinity. The model explained $56 \%$ variability in yield and $44 \%$ variability in biomass simulations ( $n=40, p<0.001$ for both cases). The higher $R^{2}$ and lower RMSE indicate better performance of the model by taking the dynamic impact of salinity on water 


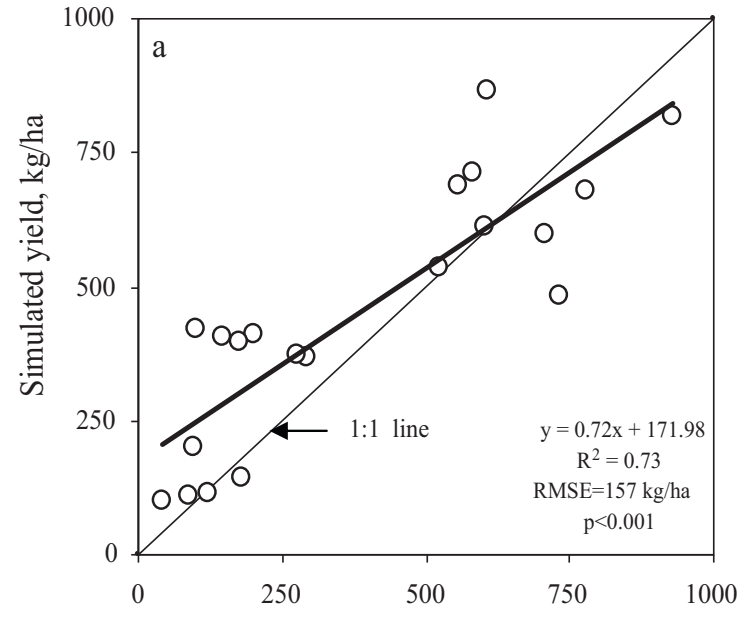

Observed yield, $\mathrm{kg} / \mathrm{ha}$

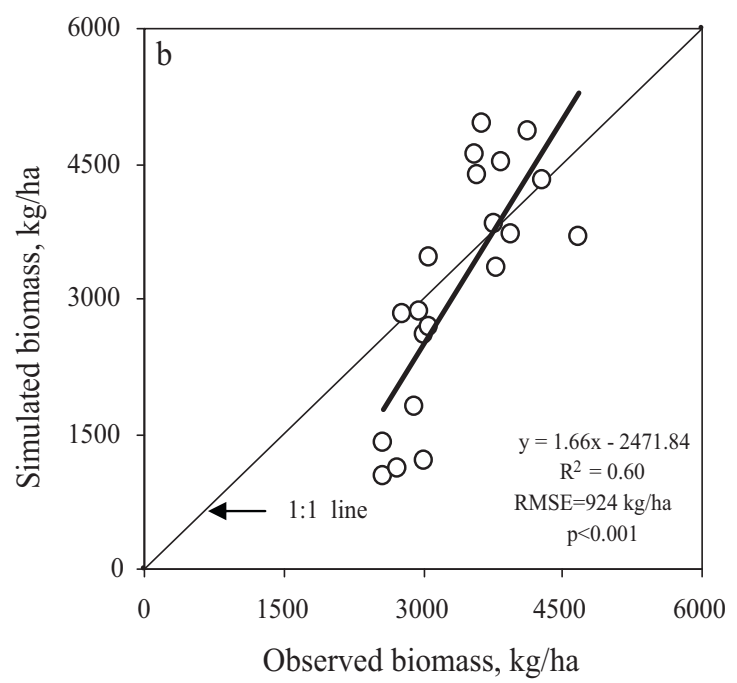

Fig. 2. Relationship between observed and simulated grain yield (a) and biomass (b) during calibration by modified model (dynamic impact of salinity).

Table 2b

Comparison of the different statistical parameters during simulation with original and modified model for biomass $(n=40)$.

\begin{tabular}{llclll}
\hline Method & $R^{2 \mathrm{a}}$ & MBE $(\mathrm{kg} / \mathrm{ha})$ & RMSE $(\mathrm{kg} / \mathrm{ha})$ & NRMSE (\%) & EF \\
\hline Original & 0.07 & 2028 & 2082 & 62.4 & -14.2 \\
Constant impact & 0.13 & 1714 & 1936 & 58.0 & -12.1 \\
Dynamic impact & 0.37 & 814 & 1042 & 31.2 & -2.8 \\
\hline
\end{tabular}

${ }^{\text {a }} R^{2}$ is for the regression with no intercept.

uptake than by taking the constant impact. The regression through the origin produced $R^{2}$ of 0.46 for yield and 0.37 for biomass simulations and a value of slope almost equal to unity for both grain yield and biomass predictions indicating that the model is good enough in terms of prediction of change in simulated value with respect to change in observed value for both yield and biomass.

The average measured yield and biomass from all the 40 sample plots were 427 and $3335 \mathrm{~kg} / \mathrm{ha}$, respectively. The simulated yield and biomass from the original model (without any modification) were 646 and $5363 \mathrm{~kg} / \mathrm{ha}$, respectively. When the model was modified by taking the constant impact of salinity, the average simulated yield and biomass were 209 and $1844 \mathrm{~kg} / \mathrm{h}$ a which were almost half of the measured yield and biomass. This indicates that the salinity impact was considered by the model and both simulated yield and biomass were reduced. But this reduction was not realistic. However, when the model was modified by taking the dynamic
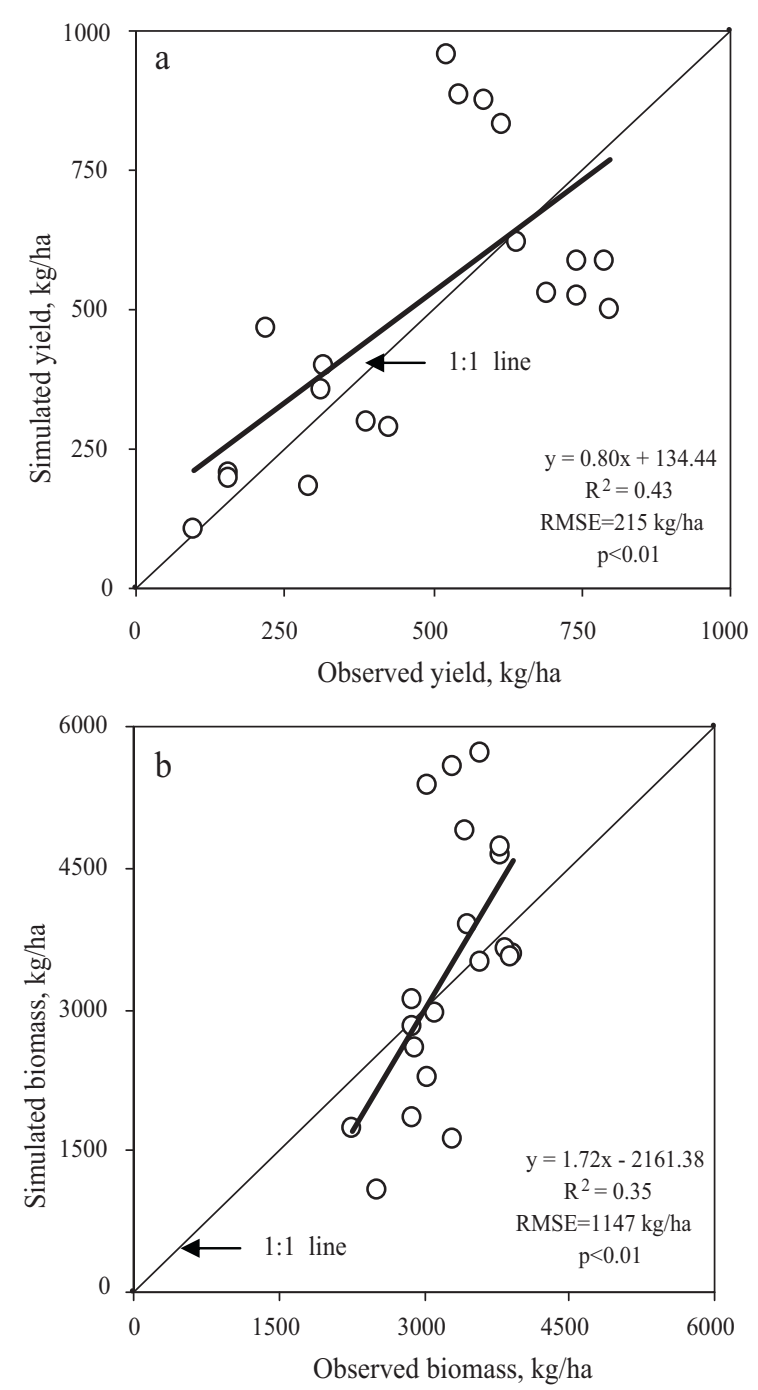

Fig. 3. Relationship between observed and simulated grain yield (a) and biomass (b) during validation by modified model (dynamic impact of salinity).

impact of salinity, the average simulated yield and biomass were very close to the measured values, 487 and $3309 \mathrm{~kg} / \mathrm{ha}$. This indicates that the reduction in yield and biomass due to salinity was more realistic. Normally, the bottom layers which have more salinity retain more water and the dilution of the salts in the soil solution is less detrimental when the salinity impact is considered dynamic rather than constant. This is the reason that the simulated yield and biomass increased when the impact of salinity on water uptake was considered dynamic opposed to when the impact of salinity was considered constant. On the other hand, when the water from top layers evaporates or infiltrates to the bottom layers, the concentration of salts becomes high in top layers and the plants are more affected when the root zone is shallow which is normally the case during early growth period of the crop. During the early phase of the crop growth, the crop physiological parameters are more affected by the decreased water potential of the rooting solution rather than the yield (Munns et al., 1995). Van Hoorn (1991) reported that in low rainfall areas, due to the evaporation of soil water during germination and emergence, salinity increases strongly in the top layer of the soil and plants are exposed to a higher salinity than during later growth stages. This adversely affects the crop growth at the early stage. However, salinity restricts root growth and makes subsoil water unavailable to crops during the later phase of growth. The low availability of water during grain filling, combined with the inability of the crop to take up water from deep saline subsoil, leads 
to reduced grain yield and the spatial variation in subsoil salinity causes spatial variation in grain yield across a paddock (Angus et al., 2001; Robinson et al., 2009).

One of the reasons of success of the van Genuchten's approach is that it modifies the water uptake for transpiration need of the crop due to water stress (which is decreased because of soil salinity) rather than modifying the lower limits of crop available water (which are increased due to salinity rendering less water availability to the plants). Rodriguez and Nuttall (2003) recommended that in heavier soils with substantial chemical constraints, similar to the soils of Wimmera/Mallee region of Victoria, Australia, it may be necessary to account for changes in transpiration efficiency rather than changing the lower limits.

The van Genuchten's approach has been used in many numerical simulation models dealing with root water uptake in saline conditions (Homaee et al., 2002) and found to be successful because it directly modifies the transpiration algorithms within the model and hence provides better estimation of water uptake. Feng et al. (2003) also used the empirical plant water uptake function of van Genuchten (1987) and reported that the simulated yield decreased with increasing irrigation water salinity. They found that the good agreement between the simulated and measured crop yield strongly suggest that the model with van Genuchten's empirical plant water uptake function can be used with confidence under saline conditions. Steppuhn et al. (2005) found that out of six response functions applied to the data from the spring-wheat, the modified-discount, van Genuchten's sigmoidal-shape response function gave the lowest root mean square error and the highest $R^{2}$ value.

The improvement in the modified model's ability to simulate wheat yield and biomass, in this study, indicates that the subsoil salinity limits crop performance in the area and its effect must be considered dynamically i.e., salinity should be varied according to its concentration in the soil water for a particular soil layer. The modified WNMM (dynamic impact of salinity) offers potential for accurately simulating yield across a paddock and can help in explaining spatial variation in grain yield at paddock scale. This is a valuable contribution to the grain growers in the salinity affected areas of the arid and semi arid regions.

\subsection{Statistical performance of the modified model}

The yield and biomass simulation performance of the original model and the modified models were compared based on comparative statistics. Tables $2 \mathrm{a}$ and $2 \mathrm{~b}$ give the values of $1: 1 R^{2}$ and other statistics for grain yield and biomass. The modification by van Genuchten's approach with dynamic impact of salinity performed better than the constant impact of salinity and the original WNMM for both grain yield and biomass simulation. It reduced the RMSE by $35 \%$ and $47 \%$ for grain yield and about $50 \%$ and $47 \%$ for biomass and the MBE by $40 \%$ and $47 \%$ for grain yield and $60 \%$ and $53 \%$ for biomass compared to the original model and the modification by taking the constant impact of salinity, respectively, indicating a big improvement in model's simulating abilities.

Overall, the modified model (dynamic impact of salinity) produced higher $R^{2}$ and $\mathrm{EF}$ values, for both yield and biomass, indicating better performance and lower values of RMSE and NRMSE indicating less spread around the 1:1 line and small error in relation to the mean. Also a lower value of MBE indicates that the model is more accurate in simulating yield and biomass and is less biased. A positive value of EF for grain yield suggests that the model provides accurate estimates of average yield. The small negative value of EF indicates that for biomass the performance of the model was not as good as that for the grain yield. However, the EF values for the modified model (dynamic impact of salinity) were reduced by about 4.5 and 5 times compared to the modified model (constant impact of salinity) and the original model, respectively, indicating about five times better performance.

\section{Conclusions}

Wheat yield simulated with the original WNMM was unrelated to the observed yield across 40 sampling points in the study paddock in the Victorian southern Mallee, Australia. The modified WNMM by incorporating the van Genuchten' stress response function for crop water uptake and considering the dynamic impact of salinity performed well in the study area compared to when the constant impact of salinity was considered. The improvement in the modified model's ability to simulate wheat yield indicates that the subsoil salinity limits crop performance in the Victorian southern Mallee. Also the success of the approach by taking the dynamic impact of salinity on transpiration indicates that in the dry condition of Victorian Mallee it becomes important to modify transpiration module of the model. The incorporation of salinity function in spatial crop models offers potential for simulating yield across a landscape and practicing precision agriculture provided adequate data on soil salinity is used as input and the impact of the salinity is considered dynamically at a daily time step.

\section{Acknowledgments}

The financial support provided by the University of Melbourne in the form of Melbourne International Fee Remission Scholarship and Melbourne International Research Scholarship is greatly acknowledged. The help extended by the Department of Primary Industries (DPI) Horsham and Birchip Cropping Group (BCG) during the experimental planning and data collection is also duly acknowledged. The authors are grateful to Dr. Yong Li, University of Melbourne for providing constructive suggestions. The project was supported by Grains Research and Development Corporation funds.

\section{References}

Abuzar, M., Rampant, P., Fisher, P., 2004. Measuring spatial variability of crops and soils at sub-paddock scale using Remote Sensing technologies. In: Proceedings of IEEE International Geoscience and Remote Sensing Symposium (IGARSS2004), Anchorage, Alaska, September 20-24, 2004, vol. III. The Institute of Electrical and Electronic Engineers, Piscataway, NJ, pp. 1633-1636.

Adiku, S.G.K., Renger, M., Wessolek, G., Facklam, M., Hecht-Bucholtz, C., 2001. Simulation of the dry matter production and seed yield of common beans under varying soil water and salinity conditions. Agricultural Water Management 47, 55-68.

Angus, J.F., Gault, R.R., Peoples, M.B., Stapper, M., van Herwaarden, A.F., 2001. Soil water extraction by dryland crops, annual pastures, and lucerne in south-eastern Australia. Australian Journal of Agricultural Research 52, 183-192.

Anon, 2004. Australian Crop Report No. 129. Australian Bureau of Agricultural and Resource Economics (ABARE), Australia.

Armstrong, R.D., Fitzpatrick, J., Rab, M.A., Abuzar, M., Fisher, P.D., O’Leary, G., 2009. Advances in precision agriculture in south-eastern Australia. III. Interactions between soil properties and water use help explain spatial variability of crop production in the Victorian Mallee. Crop \& Pasture Science 60, 870-884.

Ayers, R., Wescot, D., 1976. Water Quality for Agriculture. FAO, Rome, 97 pp.

Bashahu, M., 2003. Statistical comparison of models for estimating the monthly average daily diffuse radiation at a subtropical African site. Solar Energy 75, 43-51.

Bresler, E., MacNeal, B.L., Carter, D.L., 1982. Saline and Sodic Soils. Springer-Verlag, Berlin, $236 \mathrm{pp}$

Booltink, H.W.G., van Alphen, B.J., Batchelor, W.D., Paz, J.O., Stoorvogel, J.J., Vargas, R., 2001. Tools for optimizing management of spatially variable fields. Agricultural Systems 70, 445-476.

Cardon, G.E., Letey, J., 1992. Plant water uptake terms evaluated for soil water and solute movement models. Soil Science Society of America Journal 32, 1876-1880.

Christiansen, D.S., Reister, D.B., 1988. The Aggregate Production Profile for U.S. Crude Oil. Office of Planning and Environment, Office of Fossil Energy U.S. Department of Energy, Oak Ridge National Laboratory, Oak Ridge, TN, USA, 54 pp.

Cook, S.E., Bramley, R.G.V., 2001. Is agronomy being left behind by precision agriculture. In: Proceedings of the 10th Australian Agronomy Conference, Hobart, Australia. 
Day, P.R., 1965. Particle fractionation and particle-size analysis. In: Black, C.A. (Ed.), Methods of Soil Analysis, Part 1. American Society of Agronomy, Inc., Madison, WI, pp. 545-567.

Dixit, P.N., Chen, D., 2010a. Farm scale zoning of extreme temperatures in the southern Mallee, Victoria, Australia. Biosystems Engineering 105, 198-204.

Dixit, P.N., Chen, D., 2010b. Impact of spatially variable soil salinity on crop physiological properties, soil water content and yield of wheat in a semi arid environment. Australian Journal of Agricultural Engineering 1 (3), 93-100.

Feng, G.L., Meiri, A., Letey, J., 2003. Evaluation of a model for irrigation management under saline conditions: I. Effects on plant growth. Soil Science Society of America Journal 67, 71-76.

Fisher, P.D., Abuzar, M., Rab, M.A., Best, F., Chandra, S., 2009. Advances in precision agriculture in south-eastern Australia. I. A regression methodology to simulate spatial variation in cereal yields using farmers' historical paddock yields and normalised difference vegetation index. Crop \& Pasture Science 60, 844858.

Freeland, R.S., 1989. Review of soil moisture sensing using soil electrical conductivity. Transactions of ASAE 32 (6), 2190-2194.

Heap, J., 2002. Precision Agriculture Cropping-What is it, and What is its Future? Research Update-Southern Region-2002. SARDI, Adelaide, South Australia.

Holloway, R.E., Alston, A.M., 1992. The effect of salt and boron on growth of wheat. Australian Journal of Agricultural Research 43, 987-1001.

Homaee, M., Dirksen, C., Feddes, R.A., 2002. Simulation of root water uptake III. Non-uniform transient combined salinity and water stress. Agricultural Water Management 57, 127-144.

Incerti, M., O'Leary, G.J., 1990. Rooting depth of wheat in the Victorian Mallee. Australian Journal of Experimental Agriculture 30, 817-824.

Jacovides, C.P., Kontoyiannis, H., 1995. Statistical procedures for the evaluation of evapotranspiration computing models. Agricultural Water Management 27, 365-371.

Karlberg, L., Ben-Gal, A., Jansson, P., Shani, U., 2006. Modelling transpiration and growth in salinity-stressed tomato under different climatic conditions. Ecological Modelling 190, 15-40.

Katerji, N., van Hoorn, J.W., Hamdy, A., Mastrorilli, M., Mou Karzel, E., 1997. Osmotic adjustment of sugar beets in response to soil salinity and its influence on stomatal conductance, growth and yield. Agricultural Water Management 34 (1), 57-69.

Kiani, A., Roshani, G.A., Homaee, M., 2008. Evaluating water uptake models undersalinity and water stress conditions. Salinity, water and society-global issues, local action. New approaches for tackling the salinisation of water resources. In: 2nd International Salinity Forum, March 31-April 3, 2008, Adelaide, South Australia, Australia.

Lamsal, K., Paudyal, G.N., Saeed, M., 1999. Model for assessing impact of salinity on soil water availability and crop yield. Agricultural Water Management 41, 57-70.

Li, Y., White, R., Chen, D., Zhang, J., Li, B., Zhang, Y., Huang, Y., Edis, R., 2007. Aspatially referenced Water and Nitrogen Management Model (WNMM) for (irrigated) intensive cropping systems in the North China Plain. Ecological Modelling 203 (3-4), 395-423.

Loague, K.M., Green, R.E., 1991. Statistical and graphical methods for evaluating solute transport models. Journal of Contaminant Hydrology 7, 51-73.

Maas, E.V., 1986. Salt tolerance of plants. Applied Agricultural Research 1 (1), 12-26.

Maas, E.V., Hoffman, G.J., 1977. Crop salt tolerance-current assessment. Journal of the Irrigation and Drainage Division, ASCE 103 (IR2), 115-134.

McDonald, G.K., 2006. Effects of soil properties on variation in growth, grain yield and nutrient concentration of wheat and barley. Australian Journal of Experimental Agriculture 46, 93-105.

McWilliam, J.R., 1986. The national and international importance of drought and salinity effects on agricultural production. Australian Journal of Plant Physiology $13,1-13$.

Meinke, H., Hochman, Z., 2000. Using seasonal climate forecasts to manage dryland crops in northern Australia: experiences from the 1997/98 seasons. In: Hammer, G.L., Nicholls, N., Mitchell, C. (Eds.), Applications of Seasonal Climate Forecasting in Agricultural and Natural Ecosystems: The Australian Experience. Kluwer Academic Publishers, The Netherlands, pp. 149-160 (Module 3).

Munns, R., Rawson, H.M., 1999. Effect of salinity on salt accumulation and reproductive development in the apical meristem of wheat and barley. Australian Journal of Plant Physiology 26, 459-464.

Munns, R., Schachtman, D.P., Condon, A.G., 1995. The significance of a two-phase growth response to salinity in wheat and barley. Australian Journal of Plant Physiology 22, 561-569.

Nuttall, J.G., Armstrong, R.D., Connor, D.J., 2001a. Understanding subsoil water-use by cereals on southern Mallee soils: I. Spatial characteristics of subsoil constraints. In: Proceedings of the 10th Australian Agronomy Conference, Hobart, Australia.

Nuttall, J.G., Armstrong, R.D., Connor, D.J., 2001b. Understanding subsoil water-use by cereals on southern Mallee soils: II. Crop response. In: Proceedings of the 10th Australian Agronomy Conference, Hobart, Australia.

Nuttall, J., Armstrong, R., Connor, D., 2003a. Evaluating physiochemical constraints of Calcarosols on wheat yield in the Victorian southern Mallee. Australian Journal of Agricultural Research 54, 487-497.

Nuttall, J., Armstrong, R., Connor, D., Matassa, V.J., 2003b. Interrelationships between edaphic factors potentially limiting cereal growth on alkaline soils in northwestern Victoria. Australian Journal of Soil Research 41, 277-292.
O’Connell, M.G., O’Leary, G.J., Incerti, M., 1995. Potential groundwater recharge from fallowing in north-west Victoria, Australia. Agricultural Water Management 29, 37-52.

Poustini, K., Siosemardeh, A., 2004. Ion distribution in wheat cultivars in response tosalinity stress. Field Crops Research 85, 125-133.

Rab, M.A., Fisher, P.D., Armstrong, R.D., Abuzar, M., Robinson, N.J., Chandra, S. 2006. Advances in precision agriculture in south-eastern Australia. IV. Spatial variability in plant-available water capacity of soil and its relationship with yield in site-specific management zones. Crop \& Pasture Science 60, 885-900.

Rab, M.A., Fisher, P.D., Armstrong, R.D., O'Leary, G., Anwar, M.R., Reilly, C., Abuzar, M., Fitzpatrick, J., 2006. Managing spatial variability of grain yield at the paddock level in south-eastern Australia. In: Australian Agronomy Conference, Perth, WA September 6-14, 2006.

Rampant, P., Abuzar, M., 2004. Geophysical tools and digital elevation models: tools for understanding crop yield and soil variability. In: Supersoil 2004. 3rd Australian New Zealand Soils Conference, December 5-9, 2004. University of Sydney, Australia.

Rayment, G.E., Higginson, F.R., 1992. Australian Laboratory Handbook of Soil and Water Chemical Methods. Inkata Press, Melbourne, 330 pp.

Rengasamy, P., 2002. Transient salinity and subsoil constraints to dryland farming in Australian sodic soils: an overview. Australian Journal of Experimental Agriculture 42, 351-361.

Rhoades, J.D., Manteghi, N.A., Shouse, P.J., Alves, W.J., 1989. Soil electrical conductivity and soil salinity: new formulations and calibrations. Soil Science Society of America Journal 53, 433-439.

Rhoades, J.D., Corwin, D.L., Lesch, S.M., 1999. Geospatial measurements of soil electrical conductivity to assess soil salinity and diffuse salt loading from irrigation. In: Corwin, D.L., Loague, K., Ellsworth, T.R. (Eds.), Assessment of non-point source pollution in the vadose zone. Geophysical Monogr., vol. 108. AGU, Washington, DC, pp. 197-215.

Robinson, N.J., Rampant, P.C., Callinan, L.A.P., Rab, M.A., Fisher, P.D., 2009. Advances in precision agriculture in south-eastern Australia II. Spatiotemporal prediction of crop yield using terrain derivatives and proximally sensed data. Crop \& Pasture Science $60,859-869$

Rodriguez, D., Nuttall, J., 2003. Adaptation of the APSIM-wheat module to simulate the growth and production of wheat on hostile soils. In: Proceedings of the 11th Australian Agronomy Conference, Geelong.

Roggo, Y., Duponchel, L., Ruckebusch, C., Huvenne, J.P., 2003. Statistical tests for comparison of quantitative and qualitative models developed with near infrared spectral data. Journal of Molecular Structure 654, 253-262.

Sadras, V.O., Roget, D.K., O'Leary, G.J., 2002. On-farm assessment of environmental and management constraints to wheat yield and rainfall use efficiency in the Mallee. Australian Journal of Agricultural Research 53, 587-598.

Sadras, V., Baldock, J., Roget, D., Rodriguez, D., 2003. Measuring and modelling yield and water budget components of wheat crops in coarse-textured soils with chemical constraints. Field Crops Research 84, 241-260.

Saqib, M., Akhtar, J., Qureshi, R.H., 2004. Pot study on wheat growth in saline and waterlogged compacted soil I. Grain yield and yield components. Soil \& Tillage Research 77, 169-177.

Somani, L.L., 1991. Crop production with saline water. In: Crop Production with Saline Water. Agro Botanical Publishers, India, 308 pp.

Steppuhn, H., van Genuchten, M.Th., Grieve, C.M., 2005. Root-zone salinity: I. Selecting a product-yield index and response function for crop tolerance. Crop Science $45,209-220$.

Sudduth, K.A., Kitchen, N.R., Drummond, S.T., 1999. Soil conductivity sensing on claypan soils: Comparison of electromagnetic induction and direct methods. In: Robert, P.C., et al. (Eds.), Precision Agriculture. Proc. Int. Conf., 4th, St. Paul, MN, July 19-22, 1998. ASA, CSSA, and SSSA, Madison, WI, pp. 979990.

Tedeschi, A., Menenti, M., 2002. Simulation studies of long-term saline water use: model validation and evaluation of schedules. Agricultural Water Management 54, 123-157.

van Genuchten, M.Th., 1987. A numerical model for water and solute movement in and below the root zone. Research Report No. 121, USDA-ARS, U.S. Salinity Laboratory, Riverside, CA, USA.

van Genuchten, M.Th., Hoffman, G.J., 1984. Analysis of crop salt tolerance data. Ecological Studies: Analysis and Synthesis 51, 258-271.

van Genuchten, M.Th., Gupta, S.K., 1993. A reassessment of the crop tolerance response function. Journal of the Indian Society of Soil Science 41 (4), 730-737.

Van Hoorn, J.W., 1991. Development of soil salinity during germination and early seedling growth and its effect on several crops. Agricultural Water Managemen 20, 17-28.

Whelan, B.M., McBratney, A., 2003. Definition and interpretation of potential management zones in Australia. In: Proceedings of the 11th Australian Agronomy Conference, Geelong, Australia.

Wilmott, C.J., Ackleson, S.G., Davis, R.E., Feddema, J.J., Klink, K.M., Legates, D.R., O’Donnell, J., Rowe, C.M., 1985. Statistics for the evaluation and comparison of models. Journal of Geophysical Research 90, 8995-9005.

Xevi, E., Gilley, J., Feyen, J., 1996. Comparative study of two crop yield simulation models. Agricultural Water Management 30, 155-173.

Zhuang, J., Nakayama, K., Yu, G., Urushisaki, T., 2001. Estimation of root water uptake of maize: an ecophysiological perspective. Field Crops Research 69, 201-213. 